Endocrinology

\section{Growth hormone therapy in the Prader-Willi syndrome}

\section{W F Paterson, M D C Donaldson}

Who should receive it and when?

H November 2000 the Department of Health in England granted a licence to Pharmacia Limited for the use of their recombinant growth hormone, Genotropin (somatropin rbe), in the Prader-Willi syndrome. The indications for use were given as "improvement of body composition and growth". In this leading article we shall attempt to examine the role of growth hormone in the Prader-Willi syndrome by considering linear growth and body composition in untreated and treated individuals, the pathophysiology of the abnormal linear growth, and the scope for future research.

While the growth and body composition aspects of the Prader-Willi syndrome are important, they must be seen in the context of a disabling disorder with major implications for the individual and family. ${ }^{1}$ Therefore a brief account of the condition is in order.

\section{GENERAL ASPECTS OF THE PRADER-WILLI SYNDROME}

The Prader-Willi syndrome results from loss of an imprinted gene or genes on the long arm of chromosome 15 within the q11-13 region, usually as a result of a deletion on the paternal chromosome or less commonly to inheritance of both chromosomes from the mothermaternal disomy. ${ }^{2}$ The gene(s) presumably encode(s) a protein or proteins important for brain development, loss of which leads to a generalised brain disorder which affects the hypothalamus in particular. ${ }^{3}$ Indeed, many of the characteristic traits of the syndrome, such as hyperphagia, somnolence, skin picking, and hypogonadism, are attributable to hypothalamic dysfunction.

Severe hypotonia and weakness cause reduced fetal movements, poor feeding from birth, usually requiring tube feeding, weak or absent cry, and inertia during infancy, with developmental delay and failure to thrive. Tone and movement improve towards the end of the first year and developmental milestones are achieved, albeit delayed. By 2 or 3 years of age the hyperphagic phase of the condition begins, and unless diet is strictly controlled the child will become seriously obese. Obsessional traits, and temper tantrums in response to thwarting (often centring around food) are difficult but possible to manage during the childhood years, but in adolescence and beyond become very challenging, as the individual strives for independence. Hypogonadism causes delayed but complete puberty in females, although menses are infrequent or absent. Males almost invariably have cryptorchidism at birth and despite successful orchidopexy will require androgen replacement therapy from mid-puberty onwards if not before. The prognosis of the condition in adulthood depends on occupation and placement. If the person can be gainfully employed/occupied and live in an environment where access to food can be controlled, the outlook is reasonably good. Unfortunately many adults with the disorder develop morbid obesity, often accompanied by type II diabetes, resulting in premature death from cardiorespiratory failure. In Glasgow, since the introduction of a multidisciplinary clinic in 1991, we have seen 50 patients with Prader-Willi syndrome, age at referral varying between birth and 35 years. Of our original 50 patients, six have died between the ages of 17 and 40 years because of complications of morbid obesity with cardiorespiratory failure $(n=3)$, sepsis from skin lesions $(n=2)$, and a combination of extrahepatic portal hypertension, diabetes mellitus, and obesity $(\mathrm{n}=1)$.

\section{LINEAR GROWTH IN UNTREATED PRADER-WILLI SYNDROME}

While length at birth is normal or slightly below normal in Prader-Willi syndrome, linear growth in infancy is slow, in association with poor feeding. Thus the child is noticeably short from around the first year of life and remains short throughout childhood (mean height standard deviation score $(\mathrm{Ht}$ SDS) around -2) despite a relatively normal growth rate..$^{4-6}$ Notably, there is no enhancement of growth velocity in response to high energy intake in obese Prader-Willi subjects, in contrast to children with simple obesity. During adolescence the growth rate declines as a result of absence of the pubertal growth spurt. ${ }^{4-7}$ Thus in Prader-Willi subjects the adult height centile will be lower than the childhood height centile, with mean final heights in the UK of $147 \mathrm{~cm}(-2.8$ SD) for girls and $155 \mathrm{~cm}(-3.2 \mathrm{SD})$ for boys. $^{4}$

\section{BODY COMPOSITION}

In simple obesity, fat mass (FM) is increased while fat free mass (FFM) is normal or increased. In Prader-Willi syndrome, body composition is unusual with reduced FFM and increased FM, even in lean subjects. ${ }^{8} 9$ In addition, bone mineral content is lower than in simple obese subjects. ${ }^{8}$ Even in infancy, when body mass is low, fat content is relatively increased..$^{10}$ Energy expenditure is reduced, partly attributable to the reduction in FFM. ${ }^{9}$ Energy requirement per unit of body weight is therefore less in Prader-Willi subjects than normal controls, and this must be taken into account when calculating the optimal daily food intake. ${ }^{11}$

\section{THE PATHOPHYSIOLOGY OF ABNORMAL LINEAR GROWTH IN PRADER-WILLI SYNDROME}

The combination of impaired linear growth, abnormal body composition, and hypothalamic dysfunction in the Prader-Willi syndrome is strongly suggestive of growth hormone deficiency.

Table 1 lists the values for stimulated growth hormone from seven centres, including our own. ${ }^{12-17}$ The data are from obese and non-obese patients of different ages; in one study ${ }^{16}$ peak growth hormone (GH) levels of less than $10 \mu \mathrm{g} / \mathrm{l}$ (equivalent to $10 \mathrm{ng} / \mathrm{ml}$ or $20 \mathrm{mU} / \mathrm{l}$ ) were an inclusion criterion for receiving $\mathrm{GH}$ therapy. It is evident from the table that mean and median GH levels are consistently subnormal (less than $10 \mathrm{ng} / \mathrm{ml}$ ) in response to standard provocation agents such as insulin and clonidine.

However, scrutiny of the GH standard deviations and ranges shown in the table indicates that normal levels are found in some patients in some studies. For example, in 1991 Angulo and colleagues $^{12}$ found a wide variation in GH response to three provocative stimuli ranging from impaired to normal, whereas spontaneous GH secretion was blunted in all subjects. In a similar, larger study by this group in 1996, subnormal GH levels were reported 40 of 44 subjects, aged 2-16 years, in response to two provocative stimuli, while 17 subjects had normal levels in response to at least one test. ${ }^{18}$ As in the 1991 study, blunted 24 hour GH secretion was found in all but one subject. In contrast, Corrias and colleagues ${ }^{15}$ showed a greater $\mathrm{GH}$ response to growth hormone releasing hormone $(\mathrm{GHRH})+$ pyridostigmine or GHRH + arginine and suggest that the latter should be the test of choice to measure somatotroph responsiveness and avoid false positive results in PraderWilli subjects. The results of this study, and those of Angulo and colleagues, ${ }^{12} 18$ are consistent with the hypothalamus being the site of dysfunction.

Insulin-like growth factor 1 (IGF-1) levels were evaluated in five studies and 
Table 1 Growth hormone levels after stimulation in Prader-Willi syndrome

\begin{tabular}{|c|c|c|c|c|c|}
\hline Study & Year & No. patients & Age range $(y)$ & Stim. agent & $\mathrm{GH}(\mathrm{ng} / \mathrm{ml})$ \\
\hline \multirow[t]{3}{*}{ Angulo et al } & 1991 & 15 & $1-15.5$ & 1 & $9.4 \pm 6.2[8.0](2.5-20.4)$ \\
\hline & & & & C & $3.9 \pm 3.0[2.7](1.5-12.7)$ \\
\hline & & & & D & $5.2 \pm 3.8[3.7](1.5-12.6)$ \\
\hline \multirow[t]{2}{*}{ Grosso et al } & 1998 & 5 & $7.9-11$ & I & $8.4 \pm 3.9[8.0](3.9-13.5)$ \\
\hline & & & & C & $8.3 \pm 4.4[7.2](3.5-13.8)$ \\
\hline Carrel et al & 1999 & 54 & $4-16$ & C & $2.0 \pm 1.9$ \\
\hline \multirow{3}{*}{ Corrias et al } & 2000 & 43 & $3-22$ & C & $4.1 \pm 1.0^{*}(n=33)$ \\
\hline & & & & $\mathrm{GHRH}+\mathrm{P}$ & $14.4 \pm 3.1^{*}(n=43)$ \\
\hline & & & & $\mathrm{GHRH}+\mathrm{A}$ & $31.0 \pm 2.9^{*}(n=20)$ \\
\hline \multirow[t]{2}{*}{ Tauber et al } & 2000 & 14 & $3-14.5$ & C & $4.1 \pm 2.5[4.3](0.3-8.1)$ \\
\hline & & & & 0 & $3.6 \pm 2.3[3.6](0.2-8.6)$ \\
\hline Grugni et al & 2001 & 16 & $12.8-38.4$ & $\mathrm{GHRH}+\mathrm{P}$ & $7.3 \pm 7.2[5.3](0.4-25.1)$ \\
\hline Donaldson and Paterson & 2002 & 12 & $0.3-16.3$ & 1 & $7.2 \pm 4.2[7.2](1.8-14.0)$ \\
\hline
\end{tabular}

interpreted as low, but with considerable individual variation, in four. ${ }^{13-17}$ However, these data are difficult to interpret because of differences in assays and references ranges between the different centres. Definitive assessment of IGF-1 status in Prader-Willi syndrome will require measurement of sufficient samples in a single laboratory with robust aged related reference ranges.

It is known that in children with simple obesity, spontaneous and stimulated growth hormone levels are impaired, although IGF- 1 levels are normal. ${ }^{19}$ Is it possible, therefore, that the apparent growth hormone deficiency seen in most Prader-Willi syndrome patients is secondary to the obesity? Two studies shown in table 1 have examined GH levels in obese and non-obese patients, with conflicting results. Corrias and colelagues ${ }^{15}$ reported that, in response to three provocative stimuli, GH levels were lower in 43 Prader-Willi subjects (36 obese; seven normal weight) compared with 25 normal short children, but similar to those in 24 children with simple obesity. In contrast, Grugni and colleagues ${ }^{17}$ found blunted responses to two provocative stimuli in 16 PraderWilli subjects, in comparison with both simple obese and normal short subjects.

Pituitary morphology in Prader-Willi subjects has been examined by magnetic resonance imaging (MRI) as an indirect measure of GH function, since somatotrophs account for $50 \%$ of the anterior pituitary mass. Miller and colleagues ${ }^{20}$ found no significant difference in the height of the anterior pituitary in 15 Prader-Willi subjects, in comparison with normal controls or children with isolated growth hormone deficiency. However, in four patients the posterior pituitary bright spot was either absent or small, reflecting a physiological disturbance in the hypothalamus. Twelve of the 16 Prader-Willi subjects described by Grugni and colleagues ${ }^{17}$ had MRI performed. In contrast to Miller's group, all had abnormalities of the anterior pituitary gland and/or stalk, including nine with small anterior lobes and two with empty sellas.

To summarise, the combination of short stature, impaired growth response to obesity, and reportedly low IGF-1 levels provide evidence that the low GH levels frequently observed reflect impaired hypothalamopituitary secretion of $\mathrm{GH}$ rather than artefact related to obesity. However, the normal GH and/or IGF-1 levels and the morphologically normal anterior pituitary gland seen in some patients in some studies indicate that classical GH deficiency is not a constant feature.

\section{LINEAR GROWTH IN RESPONSE TO GROWTH HORMONE TREATMENT}

For a comprehensive summary of the response to GH therapy in Prader-Willi syndrome, the reader is referred to the excellent monograph of Urs Eiholzer. ${ }^{21}$ All studies to date have shown a significant first year response. Of particular note is the 1999 study of Lindgren and Ritzen, ${ }^{22}$ showing the results of five years GH therapy ( 0.1 or $0.2 \mathrm{IU} / \mathrm{kg} /$ day) in 18 patients aged 3-12 years. Ht SDS increased during the first year of treatment and the attained centile position was maintained thereafter. After five years therapy, mean Ht SDS remained above average for chronological age. In 2000 Eiholzer and $\mathrm{l}^{\prime}$ Allemand $^{23}$ reported a mean increase in Ht SDS of 1.8 SD in 18 prepubertal subjects aged $0.3-9.5$ years treated with growth hormone in a dose of $18 \mathrm{IU} / \mathrm{m}^{2} /$ week (age $<2$ years) or 24 $\mathrm{IU} / \mathrm{m}^{2} /$ week (age $>2$ years) for $1.5-5.5$ (median 4.0) years. However, a waning effect occurred after three years treatment. In 2000, Tauber and colleagues ${ }^{16}$ reviewed retrospectively 14 patients treated with $0.3-0.6 \mathrm{IU} / \mathrm{kg} /$ week GH for a mean of 3.6 years (range 1-9.3 years) and compared them with 14 untreated patients. In the treated group growth velocity showed the maximum increase during the first year of therapy, but remained greater than the pretreatment velocity throughout the course of treatment. Myers and colleagues ${ }^{24}$ examined the effect of two years growth hormone therapy $\left(1 \mathrm{mg} / \mathrm{m}^{2} /\right.$ day $\left(21 \mathrm{IU} / \mathrm{m}^{2} /\right.$ week $\left.)\right)$ in 35 Prader-Willi subjects, mean (range) age 9.9 (4-16 years). While height velocity increased notably from 4.7 to $10.1 \mathrm{~cm} / \mathrm{y}$ during the first year of treatment, there was a waning effect during the second year, with growth rate decreasing to $6.8 \mathrm{~cm} / \mathrm{y}$. The overall increase in Ht SDS after two years of treatment was +0.8 . Interestingly, in this study, despite basing the GH dose on surface area rather than weight to avoid excessive dosing, and using a relatively modest dose, mean IGF-l levels were above normal, suggesting supraphysiological GH replacement.

While there is now information on the short term response to growth hormone treatment, data on final height are scarce. In the long term studies described, Lindgren and Ritzen ${ }^{22}$ reported four children at final height, all within \pm 2 SD of target height (range -1.1 to +0.9 SDS). Only nine of the 28 patients described by Tauber and colleagues ${ }^{16}$ had reached final height: six untreated (mean adult Ht SDS -2.5) and three treated (mean adult Ht SDS -3.5).

In summary, short term growth hormone administration improves height velocity and height SDS in growing subjects with Prader-Willi syndrome, but there is a waning effect after $1-3$ years. There is no evidence as yet that growth hormone therapy improves final height in Prader-Willi syndrome, and in particular that growth hormone can compensate for the poor pubertal growth phase.

\section{THE EFFECT OF GROWTH HORMONE ADMINISTRATION ON BODY COMPOSITION}

Given the uncertainty as to the long term efficacy of growth hormone as a growth promoting agent in Prader-Willi syndrome, the potential metabolic benefits of treatment may provide better justification for its use in this condition. 
Data on the effect of growth hormone on body composition are encouraging, with most studies showing improvement, at least in the short term. Thus Lindgren and Ritzen ${ }^{22}$ showed a dramatic decrease in body mass index standard deviation score (BMI SDS) during the first year of growth hormone therapy. BMI then increased during a six month period of non-treatment and stabilised following reintroduction of growth hormone. However, two patients in their series developed non-insulin dependent diabetes mellitus in association with rapid weight gain while on therapy, withdrawal of growth hormone resulting in normalisation of glucose homoeostasis.

Eiholzer and $\mathrm{l}^{\prime}$ Allemand ${ }^{23}$ similarly reported normalisation of weight for height in their growth hormone treated group during the first 2-3 years of therapy, body composition then remaining the same. Tauber and colleagues ${ }^{16}$ found little change in weight SDS in their 14 treated patients, whereas BMI SDS improved slightly from 2.2 to 1.7.

Myers and colleagues' study ${ }^{24}$ of 35 Prader-Willi subjects showed a notable reduction in body fat during the first year of treatment from $46.4 \%$ to $38.9 \%$, with no further reduction in year 2. Lean body mass, however, showed a sustained increase throughout the two year period. Resting energy expenditure, reduced as expected pretreatment compared with normal children matched for surface area, increased after two years of GH. Muscle strength and agility also increased in the treated group after a year of therapy, and improvements were maintained in the second year. Importantly, parents reported an increase in physical ability, exercise tolerance, and acquisition of new gross motor skills.

In summary, the short term improvements in body composition with growth hormone therapy are encouraging. However, it is unclear whether these can be sustained in the longer term and unlikely that growth hormone treatment alone will normalise body composition. ${ }^{24}$

\section{SUMMARY AND RECOMMENDATIONS FOR FUTURE STUDY}

Growth hormone therapy given faithfully over a 1-2 year period can be expected to result in an improvement in height status and body composition in children with the Prader-Willi syndrome. However, in our experience, in the context of the wide spectrum of problems faced by these children and their families, height is seldom the principal concern. We therefore do not recommend growth hormone therapy to improve linear growth as standard practice. However, we believe that growth hormone therapy has a role where the child has showed short stature, is showing a reduced height velocity in the context of normal weight, and is from a well-motivated family in whom good compliance can be realistically expected. In the absence of clear evidence as to optimal dosage, we recommend a starting dose of $15 \mathrm{IU}(5 \mathrm{mg}) / \mathrm{m}^{2} /$ week as for classical GH deficiency, adjusting this in relation to growth response and IGF-1 levels. The current data on improved body composition are not in our view sufficiently compelling to advocate routine institution of growth hormone therapy at present, and dietary control remains the cornerstone of good management.

The improved muscle strength and agility described by Myers and colleagues $^{24}$ in growth hormone treated patients is of considerable potential interest in the treatment of preschool children with Prader-Willi syndrome. An improvement in body composition and muscle mass in this age group could have a significant impact on their mobility, with earlier achievement of gross motor milestones and in quality of life. A randomised trial of growth hormone in Prader-Willi children aged $1-3$ years is indicated, the hypothesis being that treated children would show an improvement in body composition, mobility, and quality of life, with no adverse effects in terms of cardiovascular health and glucose homoeostasis. Such a trial would only be viable if conducted on an international basis. Similarly the effectiveness of GH in improving final height outcome depends on treating a sufficient number of patients in a consistent fashion for many years. Given the small number of suitable patients in any given centre, this goal can only be achieved with disciplined collaborative study using an agreed dosage schedule.

Arch Dis Child 2003;88:283-285

\section{Authors' affiliations}

W F Paterson, M D C Donaldson, Department of Child Health, Royal Hospital for Sick Children, Yorkhill, Glasgow, UK

Correspondence to: $\operatorname{Dr} M$ D C Donaldson, Department of Child Health, Royal Hospital for Sick Children, Yorkhill, Glasgow G3 8SJ, UK; mdcd1 1@clinmed.gla.ac.uk

\section{REFERENCES}

1 Donaldson MDC. Natural history of Prader-Willi syndrome. Pharmacia International Growth Database Report No 20: Biannual Report, 2002

2 Cassidy SB, Schwartz S. Prader-Willi and Angelman Syndromes. Medicine 1998:77:140-51.

3 Donaldson MDC, Chu CE, Cooke A, et al. The Prader-Willi syndrome. Arch Dis Child 1994;70:58-63.

4 Butler MG, Meaney FJ. Standards for selected anthropometric measurements in Prader-Willi syndrome. Pediatrics 1991;88:853-60.
5 Wollmann HA, Schultz U, Graver ML, et al. Reference values for height and weight in Prader-Willi syndrome based on 315 patients. Eur J Pediatr 1998;157:634-42

6 Nagai T, Matsuo N, Kayanuma Y, et al. Standard growth curves for Japanese patients with Prader-Willi syndrome. Am J Med Genet 2000;95: 130-4

7 Hauffa BP, Schlippe G, Roos M, et al. Spontaneous growth in German children and adolescents with genetically confirmed Prader-Willi syndrome. Acta Paediatr 2000;89:1302-1 1.

8 Brambilla P, Bosio L, Manzoni P, et al. Peculiar body composition in patients with Prader-Labhart-Willi syndrome. Am J Clin Nutr 1997:65:1369-74.

9 Schoeller DA, Levitsky LL, Bandini LG, et al. Energy expenditure and body composition in Prader-Willi syndrome. Metabolism 1988;37:115-20.

10 Eiholzer U, Blum W, Molinari L. Body fat determined by skinfold measurements is elevated despite underweight in infants with Prader-Labhart-Willi syndrome. J Pediatr 1999;134:222-5.

11 Holm VA, Pipes PL. Food and children with Prader-Willi syndrome. Am J Dis Child 1976;130:1063-7.

12 Angulo M, Castro-Magana M, Uy J. Pituitary evaluation and growth hormone treatment in Prader-Willi syndrome. J Pediatr Endocrino 1991:4:167-73.

13 Grosso S, Cioni M, Buoni S, et al. Growth hormone secretion in Prader-Willi syndrome. $J$ Endocrinol Invest 1998;21:418-22.

14 Carrel AL, Myers SE, Whitman BY, et al. Growth hormone improves body composition, fat utilization, physical strength and agility, and growth in Prader-Willi syndrome: a controlled study. J Pediatr 1999;134:215-21

15 Corrias A, Bellone J, Beccaria L, et al. GH/IGF-I axis in Prader-Willi syndrome: evaluation of IGF-I levels and of the somatotroph responsiveness to various provocative stimuli. J Endocrinol Invest 2000;23:84-9

16 Tauber M, Barbeau C, Jouret B, et al. Auxological and endocrine evolution of 28 children with Prader-Willi syndrome: effect of $\mathrm{GH}$ therapy in 14 children. Horm Res 2000;53:279-87.

17 Grugni G, Guzzaloni G, Morabito F. Impairment of $\mathrm{GH}$ responsiveness to GH-releasing hexapeptide (GHRP-6) in Prader-Willi syndrome. J Endocrinol Invest $2001 ; 24: 340-8$

18 Angulo M, Castro-Magana M, Mazur B, et al. Growth hormone secretion and effects of growth hormone therapy on growth velocity and weight gain in children with Prader-Willi syndrome. J Pediatr Endocrinol Metab 1996;9:393-400

19 Argente J, Caballo N, Barrios V, et al. Multiple endocrine abnormalities of the growth hormone and insulin-like growth factor axis in prepubertal children with exogenous obesity: effect of short- and long-term weight reduction. J Clin Endocrinol Metab 1997:82:2076-83.

20 Miller L, Angulo M, Price D, et al. MR of the pituitary in patients with Prader-Willi syndrome: size determination and imaging findings. Pediatr Radiol 1996:26:43-7.

21 Eiholzer U. Prader-Willi syndrome: effects of human growth hormone treatment. In: Savage $\mathrm{MO}$, ed. Endocrine development, Vol 3. London: Karger, 2001

22 Lindgren AC, Ritzen EM. Five years of growth hormone treatment in children with Prader Willi syndrome. Acta Paediatr Suppl 1999:88:109-11.

23 Eiholzer U, I'Allemand D. Growth hormone normalises height, prediction of final height and hand length in children with Prader-Willi syndrome after 4 years of therapy. Horm Res 2000;53: 185-92.

24 Myers SE, Carrel AL, Whitman BY, et al. Sustained benefit after 2 years of growth hormone on body composition, fat utilization, physical strength and agility, and growth in Prader Willi syndrome. J Pediatr 2000;137:42-9. 